Елена Кусовац

Белградский университет

Филологический факультет

Кафедра славистики

jelena.kusovac@gmail.com
УДК 7:821.161.1.09(470)

https://doi.org/10.18485/slavistika.2020.24.1.15

Оригинални научни рад примљено 01.05.2020.

прихваћено за штампу 21.05.2020.

\title{
ПО ТУ СТОРОНУ ПРЕДМЕТА (ПРЕДМЕТНЫЙ МИР В. ПИВОВАРОВА И П. ПЕППЕРШТЕЙНА)
}

Отношение к предмету в искусстве снова становится актуальным в 60-е годы XX века: на Западе это отражается в искусстве минимализма, поп-арта и концептуализма, а в России - в творчестве неофициальных художников. В московском концептуализме предметы и вещи в большинстве случаев наделены специфическим значением и символикой, в основном определяемой советским контекстом. Поэтому и у неофициальных художников, и у концептуалистов часто речь идет о уже использованных предметах, отброшенных, о мусоре, о вещахсвидетельствах - во всяком случае о вещах, которые хранят в себе личный отпечаток его обладателя. В рамках данной статьи мы попытаемся посмотреть каким способом в творчестве концептуальных художников В. Пивоварова и П. Пепперштейна, вещи теряют свою материальность, сакрализируются и превращаются в «странные объекты», которые, посредством своей энергии оказывают сильное воздействие на человека.

Ключевые слова: московский концептуализм, визуальное искусство, В. Пивоваров, П. Пепперштейн, предметный мир, сакрализация предметов.

Attitudes towards the visual object in art become relevant again in the 1960s. In the West, this is reflected in the art of minimalism, pop-art and conceptualism, and in Russia - in the work of unofficial artists. Amongst Moscow Conceptualists, objects and things tend to have specific meaning and symbolism, mainly determined by the Soviet context. Therefore, both unofficial artists and Conceptualists often talk about objects which are already used, discarded or waste, but which still retain a personal imprint from their owners. Based on the work of two conceptual artists, V. Pivovarov and P. Pepperstein, we will demonstrate how the objects in their works lose their materiality, become sacralized and turn into "strange objects", and how these "strange objects" influence a person through their energy.

Keywords: Moscow conceptualism, visual art, V. Pivovarov, P. Pepperstein, object, sacralisation.

Эстетика концептуализма формировалась под влиянием художественной практики дадаиста и теоретика Марселя Дюшана, который еще в 1913 году в Нью-Йорке выставлял предметы домашнего обихода, освобождая их от утилитарного значения и превращая в реди-мейды. Благодаря Дюшану, изменилась позиция художника, и отныне художником мог стать не только живописец, который пишет картины, или скульптор, создающий скульптуры, а любой человек, который придумывает новое искусство на основании идеи, что стало основным стержнем поэтики концептуализма. В то же время К. Малевич пишет свои супрематические композиции, освобождается от предметности, олицетворенной в Черном квадрате, который становится не только картиной, но и таинственным знаком, иконой модернизма и, если можно так сказать, «философией искусства», где идея «черного квадрата» пригласила на диалог искусство 
XX и XXI веков. Хотя Малевич в своем позднем периоде творчества и вернулся к предметной живописи, супрематизм оставил свой след в концептуальном искусстве. Отношение к предмету в иксусстве снова становится актуальным в 60-е годы XX века: на Западе это отражается в искусстве минимализма, попарта и концептуализма, а в России - в творчестве неофициальных художников. Ключевым событием в истории концептуализма является инсталляция Дж. Кошута One and Three Chairs 1965, состоящая из стула, фотографии этого же стула и статьи из словаря с определением слова «стул». Причем, стул и фотография стула могли меняться от выставки к выставке, что зависело в основном от выбора куратора. Самое главное, чтобы сохранилась идея произведения искусства - эйдос в платоновском смысле. Отношения к самому предмету и привязанности к вещи, к «определенному стулу», Кошут не имел.

В московском концептуализме предметы имеют несколько иную функцию: независимо от того, изображены ли они на холстах, выставлены как объекты или как части инсталляции, они в большинстве случаев наделены специфическим значением и символикой, в основном определяемой советским контекстом. Поэтому и у неофициальных художников, и у концептуалистов часто речь идет о уже использованных предметах, отброшенных, нужных или забытых, предметах домашнего обихода, о мусоре, о вещах-свидетельствах - во всяком случае о вещах, которые хранят в себе личный отпечаток его обладателя. В теоретических текстах Кабакова в 1970-х годов появляется термин «плохая вещь» (Кабаков 2008: 53-55), а в искусствоведческой терминологии - плохое искусство. «Плохое искусство», по словам Е. Бобринской, - «это не направление, не эстетическая категория в строгом смысле слова. Это скорее некий вектор в развитии искусства, не всегда отчетливо осознанная тенденция, проявлявшаяся в творчестве разных художников на протяжении всей истории существования подпольной культуры и получившая к концу 1980-х годов статус своеобразного эстетического концепта, реализовавшегося в демонстративных и порой нарочито артикулированных приемах» (Бобринская 2013: 333). Основные вариации «плохого искусства» Бобринская связывает с «мусорной эстетикой», к которой обращаются Д. Краснопевцев, О. Рабин, И. Кабаков, Н. Алексеев, Б. Орлов и др.; с мотивами «руин» и «ветхости» в произведениях Б. Орлова, Комара и Меламида и др., а также с появлением «не-искусства», характерного для концептуалистской эстетики художников, принадлежащих т.н. волне «второго концептуализма» (Бобринская 2013a: 372)1. Таким образом, эстетика «плохого искусства» подразумевавала, с одной стороны, личное/интимное отношение к предметам советского быта, что встречаем на коллажах и ассамбляжах О. Рабина в виде обрывков газет, документов, листов; инсталляциях И. Кабакова (Ящик с мусором 1985, Туалет), Д. А. Пригова (газета-объект, банки с текстом), А. Монастырского (объекты Куча, Туфли). С другой стороны, в некоторых объ-

${ }^{1}$ Е. Бобринская использует этот термин для поколения художников, начавших работать на рубеже 1970-1980-х годов и имеет ввиду следующие группы: С-3 (В. Скерсис и В. Захаров), «Инспекция "Медицинская герменевтика"», «Перцы» (Л. Скрипкина, О. Петренко), а также художников Ю. Альберта, В. Захарова, И. Макаревича, Е. Елагину, Н. Паниткова и произведения так называемой «южнорусской концептуальной школы» (С. Мартынчик, Л. Войцехов, И. Чацкин, С. Ануфриев, Ю. Лейдерман, А. Петрелли и др.). 
ектах А. Монастырского, в акциях «Коллективных действий» и особенно в объектах и инсталляциях «Инспекции "Медицинская герменевтика"», эти предметы являются попутными, нейтральными, даже «агрессивно нейтральными» (Рыклин 1992: 11-70, 185-221) - (Но поздно 1986, Его глаза 1986, Поворот 1986, Товарная панель при легком искажении, 1988, Черная Эльза 1988, Книга за книгой, 1988). Таким образом, объекты и инсталляции медгерменевтов напоминают своими характеристиками эстетическую модель западного концептуализма, где первостепенным оказывается неизобразительность, минимализм, однообразность и загадочность, что вызывает «определенный дискомфорт у зрителей не столько за счет непрывычного или раздражающего внешнего облика, но главным образом за счет иных правил их восприятия, нарушающих укоренившуюся привычку обращения с искусством» (Бобринская 1994: 1).

Так, например, объект Черная Эльза вызывает у зрителя непонимание из за драматического алогического конфликта между объектом, названием и смыслом. Объект Черная Эльза представляет табуретку, сделанную из стиральных досок. Название никак не соответсвует предмету изображения, но обозначает термин, придуманный герменевтами и вошедший в Словарь московской концептуальной школь как: «принцип полной диссимиляции обстоятельств. Отчасти соответствует «плевральному шоку», как он описан в Волшебной горе Т. Манном. Ч.Э. (максимум энтропии) и Черный Гонконг (минимум энергии) являются разведенными частями Второго начала термодинамики. Между ними простирается Парижско-Юрская дорога». Интересно, что Черная Эльза появляется и в психоделическом романе Мифогенная любовь каст как странный прибор, который должен был обеспечить русскую победу в войне. «Назвала она этот прибор «Черная Эльза»: специально дала ему немецкое женское имя, считая, что немецкая смерть должна иметь немецкое имя» (Ануфриев, Пепперштейн 2010: 448).

С помощью алогической цепочки между основным предметом (табурет), материалом, из которого он сделан (стиральные доски), названием (Черная Эльза) и символическим представлением названия, вошедшим в словарь, обессмысливается весь дискурс. Не важно, что весь концепт вещь-название-описание намекает на инсталляцию Кошута, где показан стул-фотография стула-словарная статья.

Подобную мистификацию встречаем и в инсталляции Медгерменевтов Проблема трофея (1993), показанной на выставке Заложники пустоты, в которой трехмерность «холстов» образуется благодаря трём натянутым белым полотнам, за которыми находятся спрятанные вещи. Таким образом, художники, с одной стороны, обыгрывают тему пустоты, отсутствия, забвения (белые натянутые холсты в виде картин), а с другой - представляют материальность скрытых предметов, превращая их секретность в сакральность. В альбоме Пивоварова 2005 года Праздники, в листке Праздник бельх покрывал, встречается та же тема: «В этот день мебель в доме и зеркала покрываются белыми покрывалами. Это день поминовения умерших родных и друзей. Целый день проводится в глубоком молчании» (Пивоваров 2006: 56).

Многие альбомы Пивоварова посвящены темам одиночества, забвения, искания художественной и экзистенциальной идентичности, ностальгии (Лицо 1975, Проект для одинокого человека, Конклюзии) и некой абсурдной кореля- 
ции между человеком и "умом не постижимым” миром. Работы Пивоварова рассчитаны на долгое и пристальное рассматривание, на долгое созерцание, поскольку зритель охвачен атмосферой картин. Одиночество, изоляция, монотонность, бессобытийность и пустотные миры Пивоварова представлены в метафорических и условных образах. Пивоваров выбирает для своих метафизических пространств одиноких героев-эйдосов, иногда человекообразных, но часто и геометризованые силуэты без лица и эмоций, в которых обитает душа². Его эстетический субъект, «художник-персонаж», превращается в «маленького человека» в прямом и в косвенном смысле. В его художественном эксперименте Микрогомус 1979, «задуманном как часть большого альбомного «романа» (Пивоваров 2014: 78), Микрогомус ощущает ужас и угрозу от обыкновенных бытовых вещей вокруг него, за которыми он пристально наблюдает и чью энергию «злых точек» постояно ощущает, пока сам не исчезнет, спрятавшись в спичечную коробку в ящике рабочего стола. Он уходит в ландшафт, внутри спичечной коробки, что можно считать экспериментом в пределах картинного пространства, характерного для большинства неофициальных художников того времени, прежде всего Эрика Булатова. Однако, отношение Пивоварова к одиночеству является амбивалентным. Оно представлено и как высшая степень аскетизма ${ }^{3}$, в котором человек остается наедине с самим собой, со своей душой, с сознанием и восприятием личных отношений с окружающим миром. Он прячется за кулисы собственной души, потому что «там просторно, загадочно и прохладно, и там проживает бесконечность» (Пепперштейн 2014: 8). По его мнению, одиночество имеет четыре ступени:

1. Трагическое или экзистенциальное одиночество

2. Меланхолическое или космическое одиночество

3. Созерцательное или метафизическое одиночество

4. Радостное или абсолютное одиночество.

Все степени одиночества Пивоваров показал в своих проектах Проект жилого помещеения для одинокого человека, Режим дня одинокого человека, Проект предметов повседневного обихода для одинокого человека, Проект снов для одинокого человека и др. Обсуждая разные ступени одиночества, художник пишет, что «Показанные проекты, предлагающие предельную несвободу на уровне актуального бытия, должны привести к достижению четвертой ступени одиночества, которая, хотя и совпадает с физической смертью одинокого человека, является тем не менее обретением подлинной свободы и соединения с бесконечным» (Пивоваров 2001: 105). Нам кажется, что последние два типа одиночества тесно связаны с темой пустоты, которая становится одной из центральных тем в творчестве «Инспекции »Медицинская герменевтика"» и «Коллективные действия». Одиночество Пивоварова прежде всего показано в пространстве комнаты, поскольку комната для него обозначала именно тот уголок мира, в котором обитает душа, независимо от того, где эта комната находится - на Маросейке, в мастерской Пивоварова, или в Праге, в которую Пивоваров

\footnotetext{
${ }^{2}$ Имеется ввиду картина В. Пивоварова Как изобразить жизнь души? (1975).

3 Это найболее показано в альбоме В. Пивоварова Отиельники (2003).
} 
„убежал” в 1982 году. «Комната души» Пивоварова, возможно, повлияла и на развитие жанра комнаты как инсталляционного пространства у Кабакова и И. Наховой ${ }^{4}$, а также на пространство больничных палат и психоаналитических кабинетов Медгерменевтов.

Самые ранние альбомы Пепперштейна раскрывают также тему одиночества и изоляции, только его герои застревают не в шкафах, как у Кабакова, или в спичечных коробках Пивоварова, а в бутылках (альбом Бутыллочные человечки 1979) и там устраивают свой внутренний мир.

В сознании Пепперштейна память занимает важное место и нередко отражается в старинных вещах - символах ушедшей эпохи: «Но, слава богу, есть еще на свете рассохшиеся кухонные столики, узорчатые клеенки с горелыми кругами от горячих чайников и сковородок, подвешенные под потолком велосипеды, дырявые ситцевые занавески, книги, календари и прочие вещи, без которых продолжить жизнь не имело бы никакого смысла» (Пепперштейн 2006: 46). Наряду с этим встречаются и рухлядь, помойки, кладовые, чердаки, подвалы с тайнами, но и «перламутровые ботинки со светящимися шнурками», «серебристые плейеры с пушистыми наушниками», «крошечные мобильные телефоны со светящимися экранчиками ... «(Пепперштейн 2006: 47)». Предметный мир описывается как художественная инсталляция, в которой сочетаются прошлое и настоящее, советское и современное, коммунальный быт и квартиры в разгаре евроремонта. У автора постоянно ощущаются ностальгические настроения, характерные, прежде всего, для людей и обществ, потерпевших крах, смену власти, или крушение самого государства. И когда речь идет о ностальгии, мы не имеем ввиду ее изначальный смысл как «тоска по родине, по родному дому» (Ожегов, Шведова 1998: 422), а второй смысл. Так, ностальгия у Пепперштейна преставляется как тоска о прошлом, о пережитом, об утраченном: «на стыке этих двух вещевых миров они и жили, причем старое и уходящее демонстрировало гораздо большую прочность, оно хорошо держалось и пустило глубокие корни, которые достигали самой сердцевины жизни, тогда как новое быстро ломалось, устаревало или выходило изм моды и заменялось другим новым» (Пепперштейн 2006: 46).

Свое отношение к предметам и вещам, Пепперштейн наиболее точно описал в тексте Пассо и детриумфация. Ключевой вопрос Пепперштейна: может ли вещь вообще или какая-либо вещь по отдельности обладать определенной внутренней активностью?

Предметный мир у Пепперштейна - очень богатый и разнородный. Он описывает предметы с такой подробностью, до мельчайших деталей, будто проникая в них с аппаратом окулиста. Предметы и вещи в его поэтике обладают собственной аурой, особой энергией, которая влияет на окружающих. Используя терминологию В. Руднева, их можно назвать «странными объектами» (Руднев 2014), поскольку они оказывают сильное воздействие на человека. В своем тексте Пассо и детриумфация. Попьттка классификации по принципу отношений с предметом Пепперштейн выделяет два типа людей: тех, которые несут на себе «бремя «ненависти вещей», и тех, которых можно назвать «любимцами вещей».

\footnotetext{
${ }^{4}$ О жанре «комнатах» в московском концепутализме см. в сборнике МАНИ 1987. Комнаты.
} 
Примером первых для Пепперштейна является Кафка, других - Томас Манн. Автор предлагает и третью подгруппу, которую «составляют люди, не испытывающие на себе какого-либо повышенного или определенно окрашенного отношения со стороны вещей, но зато сами пытающие глубокую и захватывающую «страсть к вещам». В третьей подгруппе автор выделяет еще два типа: «зафиксированные» и «расплывчатые». Первые, по авторскому мнению, рассматривают предмет как «объект страсти», «в жертву которому приносят свое обожание». Таким типом объекта является Заир Борхеса, которого Пепперштейн определяет как «сверхинтенсивный предмет, настолько интенсивный, что он завладевает сознанием каждого, кому лишь стоило бросить на него взгляд». Другому типу, расплывчатому, принадлежит Пруст. Пепперштейн считает, что «"расплывчатый тип" отличается от "зафиксированного" тем, что то внимание, которое в случае фиксации относится в первую очередь за счет какой-то определенной категории предметов (денег, драгоценностей, тростей, ключей, спичечных этикеток) или даже скапливается вокруг какого-либо одного конкретного предмета (любимой картины, монеты, драгоценности, трости, кресла), предстает перед нами в постоянном движении. Оно (это аффектированное внимание) свободно перемещается с предмета на предмет. Аффект при этом не становится слабее» (Пепперштейн 1998). Хотя автор в своих интерпретациях и самоинтерпретациях не определяет свое отношение к предмету, нам кажется, на основании его поэтики, что он принадлежит к «расплывчатому типу». Пепперштейн превращает мир предметов в мир вещей, а мир вещей - в мир идей. В своей Реалогии (Вещеведению) М. Эпштейн обозначает разницу между предметом и вещью следующим образом: «Предмет превращается в вещь лишь по мере своего духовного освоения, подобно тому, как индивидуальность превращается в личность в ходе своего самосознания, самоопределения, напряженного саморазвития» (Эпштейн 2003: 346-350). Вещи теряют свою материальность, они сакрализируются в пепперштейновской прозе и становятся «материальными выражениями» своих символических свойств: трофеями, атрибутами и сувенирами. Они воздействуют, благодаря своему сакральному характеру. Вещи для Пепперштейна есть смысловые, а не материальные единства.

Они часто вступают в роли помощников и союзников: «Разница в том, что все мои вещи от Помощников получены или сами есть Помощники - они все из Нашего Собственного, а вот у тебя - настоящий Трофей, от врага принесенный. Считается, что у такого оружия особые возможности. Неисчерпаемые. Но и обращаться с ним надо более осторожно: начеку надо быть. Вообще-то говоря, иметь у себя такую вещь - смертельный риск. Но есть одно важное обстоятельство: считается, что тот, кто получил Трофей в свой День Рождения, тому он не может принести никакого вреда, а только лишь пользу. Более того, Трофей, который человек заполучил на свой День Рождения, называется "Подарком на День Рождения". И это уже не просто Трофей, он приобретает новое качество, как бы сродняется со своим хозяином и называется Атрибут. Иметь такой Атрибут и почетно и выгодно. Говорят, он не только при жизни, но и после смерти полезен. При особо удачном стечении обстоятельств Трофей, который стал Атрибутом, может сделаться также Сувениром. А если у тебя появился спелый, нефальшивый Сувенир - это значит, никто никогда не сможет хозяй- 
ничать у тебя в мозгах. А это, Дунай, редкость. Потому что, покамест мы не обзавелись хорошим Сувениром, в голову нам лезут все, кому не лень, как в общественный туалет. У тебя, правда, в голове Советочка, но она спит и во сне советы подает. А такие вещи, как эта (Поручик снова указал на серую веревку), не спят никогда. Они всегда начеку. Советов они тоже никаких не подают - они всегда действуют САМИ» (Ануфриев, Пепперштейн 2010: 331). Таким образом, предметы меняют свою профанную функцию на сакральную. Р. Кайуа в своей книге Миф и человек. Человек и сакральное подчеркивает заразительную и опасную силу сакрального, воздействующую на того, кто к этим предметам прикасается: «Итак, в своей элементарной форме сакральное представляет собой прежде всего опасную, непонятную, трудно управляемую и в высшей степени действенную энергию» (Кайуа 2003: 153).

Трофей в Словаре терминов московской концептуальной школь определяется как «предмет, вынесенный из глубин галлюциноза»: «Я думаю, твой наставник, который готовил тебя, объяснил тебе, что для тебя было бы максимально выгодным, чтобы этот Трофей стал твоим Атрибутом, а впоследствии Сувениром. Для этого не пользуйся им, не думай о нем, ничего с ним не делай, никак к нему не относись, не обращайся к нему с речами, не наделяй его именем, не спрашивай его ни о чем, не проси у него ничего, не приказывай ему, не делись с ним своими мыслями, просто держи его у себя, вот как ты держишь при себе этот бинокль» (Ануфриев, Пепперштейн 2010: 337). Вещь, превратившись в Трофей, потом в Атрибут и в конце в Сувенир, приобретает высшую силу, особые возможности, действующие даже после смерти. Таким образом в вещи отражается замысел Бога относительно этой вещи. В. Н. Топоров, ссылаясь на речение Августина «вещи таковы, какими их видит Бог», считает, что «вещь в силу описанного подобия ведет человека к Богу, и человек, пользуясь вещами по своим «низким», собственно человеческим нуждам, должен помнить, что через них он вступает в общение с Богом и Бог через них говорит с человеком» (Топоров 1993: 70-94). Расуждая о таинственных свойствах предметов, воздействующих на человека, т.н. «души предмета», с его тайной и неузнаваемой «сущностью», Пепперштейн придумывает слово «пассо», обозначающее «неопознаваемую душу неодушевленного» и пассивную активность предмета (Пепперштейн, Монастырский 1999: 176). С другой стороны, слово «ДЕТРИУМФАЦИЯ» означает «Состояние, в котором та или иная вещь освобождается от своего бытия в качестве именно этой вещи, выходит из состояния «триумфа», которым является ее встроенность в определяемость мира» (Пепперштейн, Монастырский 1999: 176). Кажется, что этот «прием» можно применить на некоторые предметы на картинах Пивоварова, которые, «детриумфировавшись», принимают на себя энергию некоего Абсолюта, Духа, Эйдоса. В альбоме Желтылй Пивоварова все начинается с Большого яйца (желтого цвета) и продолжает действовать, вселяться в пространства сознания (одного человека), в пространства быта (комнаты как верный мотив), передавая свою энергию-луч, силу предметам, которые трансформируются в вещи, а потом в Атрибуты. Кажется, что именно детриумфация - это звено между вещью и Атрибутом. К. Кобрин в тексте Желтое и желтый, говоря о альбоме Пивоварова, обращает внимание на объяснительную записку к цветовой гамме 
около желтого прямоугольника ${ }^{5}$ в которой написано «Цвет Духа, части Бога», из чего следует, что цвет Духа - именно желтый: «Дух витает, где хочет. Иногда он материализуется в виде настольной лампы, торжественно озаряющей аллегорию Дома. Это Дом-Духа, его торжество и апофеоза; «Лампа освещала комнату теплым уютным светом». Уют является предикатом Дома Духа, так же, как аллегорией его является чайная чашечка с блюдцем» (Кобрин, Пивоваров 2006: 131). Все это можно отнести и к другим вещам в пивоваровской предметной сокровищнице: желтому ножу (Но иногда какой-нибудь предмет становился желтыл), желтому креслу (И иногда у меня являлась надежда), присваивающими энергию Желтого и теряя свою изначальную функцию предмета, превращаясь в Атрибут. И здесь вполне уместно было бы применить магриттовский прием: что это не нож и это не кресло, ${ }^{6}$ т.е. что это не только нож и это не только кресло. Предметы-атрибуты появляются на картинах Пивоварова в цикле картин Эйдосы с атрибутами (2009). Бытовые предметы, вроде ножа, лампы, чернильницы, журнала, не представляют только материальную характеристику предметов, а скрытую, сакральную, внутреннюю душу предметов. Ж. Бодрияр в своей книге Система вещзей (Бодрияр 2001: 32) считал, что вещи, помимо своих практических функций, обладают способностью вбирать в себя душевный опыт человека, и именно такую функцию вещи мы имеем ввиду, когда речь идет о предметном мире на картинах В. Пивоварова и в литературном творчестве П. Пепперштейна, поскольку они, как бы отрицая свою функциональность, выражают в себе свидетельство, память, воспоминания и ностальгические ощущения и могут оказать влияние на того, кто ими обладает: «Вещь вышла из себя. Вещь стала не в себе» (Ануфриев, Пепперштейн 2010: 329); «Сегодня, наверное, праздник. Сегодня получишь Предмет. Ты сможешь сжимать в ладошке собственную судьбу. Пройдут миллиарды мгновений, проскочат десятки лет, И вас похоронят вместе в простом деревянном гробу. И после, в неведомых жизнях, в посмертных сюжетах, в мирах, Свой сувенир повсюду будешь таскать с собой. Стирается память. Останутся только ворсинки на швах. Cepoe, Плотное, Узкое. Кисточка. Гвоздик. Отбой» (Ануфриев, Пепперштейн 2010: 330). «Мне эта вещь не нужна. Но то, что ты обладаешь ею, меняет отношение к тебе» (Ануфриев, Пепперштейн 2010: 337).

Атрибуты из мира идеи снова переходят в материальный мир, становятся Сувенирами $^{7}$ - памятниками прошлого, но обладающими энергией защиты: «Вот разве что он уничтожил твой Сувенир. Теперь у тебя будут возникать серьезные проблемы с памятью» (Ануфриев, Пепперштейн 2010: 652). Такого рода предметы присутствуют на картинах Пивоварова, Пепперштейна, а также и в их прозе. В. Пивоваров их называет сакрализаторамы, подразумевая под этим «специальные охранные приспособления для защиты «внутреннего» от «внешнего».

\footnotetext{
${ }^{5}$ Имеется в виду альбом В. Пивоварова под названием Философу, Письмо №3.

${ }^{6}$ Относится к работе Р. Магритта Вероломство образов 1928-1929 с надписью Это не трубка.

${ }^{7}$ Сувенир (фp. Souvenir - воспоминание, память) - предмет, предназначенный напоминать о чём-то. В Словаре терминов московской концептуальной школь, медгерменевты сувенир определили как «тип объекта, консервирущий в себе память об определенном событии (опредмеченная память)» («Инспекция «МГ» 1998: 82).
} 
«Сакрализаторами могут быть самые обыкновенные предметы быта. Имея на себе сакрализатор, например, повесив на нос сковородку, а на уши - сапожные щетки, можно появляться в самых «загрязненных» общественных и спиритуальных пространствах и быть защищенным от опасных невидимых излучений» (Пивоваров 1979). Оказывается, что энергия предмета может быть угрожающей и опасной с одной стороны, но защищающаей с другой.

Многие предметы заимствованы из сказок: так появляются волшебные сапоги или скатерть-самобранка со своей охраняющей функцией: «Тем более, что мне никакого труда бы не составило дать тебе с собой Скатерть-Самобранку: она бы тут и тебя поддержала бы, как следует, и народу бы тут спасла видимо-невидимо от голодной смерти», или шапка-невидимка в инсталляции С. Ануфриева ${ }^{8}$.

Одной из важных характеристик пепперштейновской прозы является антропоморфизм, а некоторые изложения и рассказы ведутся от лица неодушевленного предмета: Рассказ зеркальиа, Продолжение истории потерянного зеркальца. Начав с того, что природа вещей в какой-то мере антропоморфна и что «человека связывает с окружающими его вещами такая же (при всех оговорках) органическая связь, что и с органами его собственного тела, и в «собственности» на вещи всегда виртуально присутствует тенденция вбирать в себя их субстанцию через поедание и "усвоение"» (Бодрияр 2001: 33), автор считает, что именно зеркало самым лучшим образом отражает эту связь, ведь благодаря ему человек может видеть свое отражение и лучше познать самого себя. Во всей глубине галлюциноза герои Пепперштейна анализируют, декодируют и деконструируют знаки и символы. Так, например, девушка Катя Сестролицкая в поиске своего собственного я, оглядываясь в зеркале, видит «чудесное лицо Маши Аркадьевой, ее золотистые волосы, ее влюбленные глаза - словно два зеркала, обнявшие вагончик с двух сторон, сообщались меж собою по двум каналам восхищения. Два полурастворившихся «я» отразились друг в друге», что способствует «удвоению» я, мотивом двойничества, столь характерном для пепперштейновской прозы. Зеркало здесь является двойным обманщиком: с одной стороны, оно порождает восприятие без объекта, а с другой - восприятие Другого.

Зеркало и оптические приборы являются одними из самых употребляемых объектов в поэтической иконографии автора. Неслучайно М. Рыклин заявил, что «Вся проза Пепперштейна в той или иной мере зеркальна. Даже если зеркало не становится действующим лицом, все непрерывно отражается во всем. Невозмутимая зеркальность позволяет избежать психологизации и так называемой «лепки характеров», которой обычно кичатся профессиональные литераторы. Мир зримого и мир текста в этой прозе строго разделены» (Рыклин 1998). Все эти зеркала, монокли, бинокли, стекляные объекты, линзы, оптические приборы, стетоскопы, эпруветы относятся к зрению и к концепту наблюдения и эта «смена ракурса» приводит к появлению «включенного наблюдателя»,

${ }^{8}$ Имеется ввиду инсталляция Шапка-невидимка (1997) С. Ануфриева: на пустом пьедестале не находится ничего, кроме названия инсталляции. Используя сказочный мотив шапки-невидимки и ее волшебное свойство делать невидимым того, кто ее надевает, он наделяет ее еще одной функцией (кроме субъекта действия) - функцией объекта, который, уничтожив самого себя, оставляет за собой пустое пространство. 
агента, изучающего всех и все вокруг себя, включая и себя самого, что привело к выраженной саморефлексии и методу самоинтерпретации, теоретической практике, столь важной для московских концептуалистов.

\section{Использованная литература}

Бобринская, Екатерина. Концептуализм. Москва: Галарт, 1994.

[Bobrinskaia, Ekaterina. Kontseptualizm. Moskva: Galart, 1994]

Бобринская, Екатерина. Чужие? Неофициальное искусство: Мифы, стратегии, концепции. Москва: Breus, 2013.

[Bobrinskaiā, Ekaterina. CHuzhie? Neofitșial'noe iskusstvo: Mify, strategii, kontsept șii. Moskva: Breus, 2013]

Бодрияр, Жан. Система вещей. Москва: РУДОМИНО, 2001.

[Bodriiâ,, ZHan. Sistema veshcheǐ. Moskva: RUDOMINO, 2001]

Кабаков, Илья. 60-70-е... Записки о неофициальной жизни в Москве. Москва: Новое литературное обозрение, 2008.

[Kabakov, Il'iâ. 60-70-e... Zapiski o neofitsial'noĭ zhizni v Moskve. Moskva: Novoe literaturnoe obozrenie, 2008]

Кайуа, Роже. Миф и человек. Человек и сакральное. Москва: ОГИ, 2003.

[Kaĭua, Rozhe. Mif i chelovek. CHelovek i sakral'noe. Moskva: OGI, 2003]

Кобрин, Кирилл. Желтое и Желтый в: Пивоваров В., Едоки лимонов. Москва: XL Галерея, 2006.

[Kobrin, Kirill. ZHeltoe i ZHeltyı̆ v: Pivovarov V., Edoki limonov. Moskva: KHL Galereia, 2006].

Ожегов, С. И., Шведова Н. Ю. Толковый словарь русского языка. Москва: ИТИ Технологии, 1998.

[Ozhegov, S. I., SHvedova N. IU. Tolkovyı̌ slovar' russkogo iâzyka. Moskva: ITI Tekhnologii, 1998]

Пепперштейн, Павел. Вступительный текст в каталоге Виктор Пивоваров, Книга I. Artguideeditions, Музей МАГМА, 2014.

[Peppershteĭn, Pavel. Vstupitel'ny̌̆ tekst v kataloge Viktor Pivovarov, Kniga I. Artguideeditions, Muzeĭ MAGMA, 2014]

Руднев, Вадим. Странные объекты, Феноменология психотического мышления. Москва: Академический проект, 2014.

[Rudnev, Vadim. Strannye ob"ekty, Fenomenologiiā psikhoticheskogo myshleniiā. Moskva: Akademicheskiı̌ proekt, 2014]

Рыклин, Михаил. Диета старика. Москва, 1998.<http://lib.ru/PROZA/PEPPERSHTEJN/ dieta_starika.txt>30.04.2020.

[Ryklin, Mikhail. Dieta starika. Москва, 1998. <http://lib.ru/PROZA/PEPPERSHTEJN/ dieta_starika.txt>30.04.2020.

Рыклин, Михаил. Террорологики. Москва-Тарту: Эйдос, 1992.

[Ryklin, Mikhail. Terrorologiki. Moskva-Tartu: Ėŭdos, 1992]

Топоров, В.Н. Вещь в антропоцентрической перспективе. Москва: Aequinox, 1993, 70-94.

[Toporov, V.N. Veshch' v antropoțentricheskoŭ perspektive. Moskva: Aequinox, 1993, 70-94] 
Эпштейн, Михаил. Проективный философский словарь: Новые термины и понятия. Под ред. Г.Л. Тульчинского и М.Н. Эпштейна. СПб.: Алетейя, 2003.

[Ėpshteĭn, Mikhail. Proektivnyı̆ filosofskiı̌ slovar': Novye terminy i poniâtiiâ. Pod red. G.L. Tul'chinskogo i M.N. Ėpshteǐna. SPb.: Aleteĭiā, 2003]

\section{Источники}

Ануфриев, С., Пепперштейн, П. Мифогенная любовь каст. Москва: Ад Маргинем Пресс, 2010.

[Anufriev, S., Peppershteīn, P. Mifogennaiā liūbov' kast. Moskva: Ad Marginem Press, 2010]

Пепперштейн, Павел. Пассо и детриумфация. [В:] Диета старика. Москва: 1998. $<$ http://lib.ru/PROZA/PEPPERSHTEJN/dieta_starika.txt> 30.04.2020.

[Peppershteĭn, Pavel. Passo i detriumfatsiia / Dieta starika, Moskva: 1998. <http://lib.ru/ PROZA/PEPPERSHTEJN/dieta_starika.txt> 30.04.2020.

Пепперштейн, Павел. Свастика и пентагон. Москва: 2006.

[Peppershtel̆n, Pavel. Svastika i pentagon. Moskva: 2006]

Пепперштейн, Павел. Словарь терминов московской концептуальной школы. Сост. А. Монастырский, Москва: 1999.

[Peppershteĭn, Pavel. Slovar' terminov moskovskoř konţeptual'noř shkoly. Sost. A. Monastyrskiǐ, Moskva: 1999]

Пивоваров, Виктор. Альбом «Сакрализаторы», 1979.

[Pivovarov, Viktor. Al'bom «Sakralizatory», 1979]

Пивоваров, Виктор. Едоки лимонов. Москва: XL Галерея 2006.

[Pivovarov, Viktor. Edoki limonov. Moskva: KHL Galereiā 2006]

Пивоваров, Виктор. Книга I. Art guide editions. Музей МАГМА, 2014.

[Pivovarov, Viktor. Kniga I. Art guide editions. Muzeĭ MAGMA, 2014]

Пивоваров, Виктор. Проект биографии одинокого человека. Из проектов для одинокого человека. [В:] Влюбленный агент. Москва: Новое литературное обозрение 2001.

[Pivovarov, Viktor. Proekt biografii odinokogo cheloveka. Iz proektov dliā odinokogo cheloveka // Vliưblennyı̌ agent, Moskva: Novoe literaturnoe obozrenie 2001]

Јелена Кусовац

С ОНЕ СТРАНЕ ПРЕДМЕТА

(ПРЕДМЕТНИ СВЕТ В. ПИВОВАРОВА И П. ПЕПЕРШТАЈНА)

\section{Резиме}

Полазећи од чињенице да предметни свет код московских концептуалиста заузима значајно место, у овом раду смо се претежно бавили односом према предмету/ствари у радовима најзначајних концептуалних уметника Виктора Пивоварова и Павла Пеперштајна. С обзиром да «лоша уметност» представља једну од важних естетских концепција коју су развијали незванични уметници у периоду од 1960-х до 1980-х, сматрамо да је та концепција 
доживела одређену транформацију у делима млађих концептуалних уметника. Предмети из совјетске свакодневице, приказани на сликама или коришћени у инсталацијама незваничних уметника, повезивани са «естетиком ђубрета», код московских концептуалиста млађе генерације бивају неутрализовани, минимализовани али уједно и лишени сопствене материјалности. Предмети се сакрализују, претварају у сувенире и трофеје, добијајући притом нови, виши смисао, а њихово деловање на посматрача/читаоца бива пренесено изван естетских оквира у «поље свести».

Кључне речи: Московски концептуализам, П. Пеперштајн, В. Пивоваров, визуелна уметност, предметни свет, сакрализација предмета. 